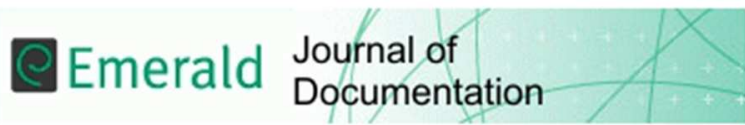

Response to Cult of the "I"

\begin{tabular}{|r|l|}
\hline Journal: & Journal of Documentation \\
\hline Manuscript ID & JD-03-2017-0038.R2 \\
\hline Manuscript Type: & Article \\
\hline Keywords: & $\begin{array}{l}\text { iSchools, iField, Library and Information Science, Branding, } \\
\text { Information science, Response }\end{array}$ \\
\hline \multicolumn{2}{|l}{} \\
\hline
\end{tabular}

SCHOLARONE $^{\text {m }}$

Manuscripts 


\section{Response to Cult of the "I"}

\section{Introduction}

In the "Cult of the 'I'" (Golub, Hansson and Seldén, 2017) three Scandinavian iSchools are compared with three American. The purpose is ambitious, to "establish any potential differences between American and Scandinavian iSchools" (50). This is pursued through a statistical analysis of curricula together with a qualitative study of three documents. The current text is a response from researchers active at the only certified Swedish iSchool, the Swedish School of Library and Information Science (SSLIS) at the University of Borås, one of three Scandinavian schools studied. The "Cult of the 'I'" article is written by colleagues at another Library and Information Science (LIS) department in Sweden, situated within the School of Cultural Sciences, Linnaeus University.

As information scientists we sometimes perform research on research, primarily within scholarly communication and bibliometrics. In such cases there is a certain distance to that which is studied. There is also a strong tradition of self-reflection within LIS, investigating our own field. However, such practices also involve ethical aspects. If the intention is to study colleagues, their educational practices and discourses at other departments in the same country, then it is reasonable to expect that a rigorous and transparent approach to research is adopted (as should always be the case). This is particularly pertinent if that research is submitted for publication to a leading journal. In the "Cult of the "I"" article, there is a persistent tendency of Scandinavian schools being portrayed in a negative way. This is established from the start as the word "cult" usually describes socially deviant groups, not a cluster of higher education institutions.

Such negative starting points are also involved in choice of the theoretical perspective of organisational symbolism. As described by the authors, this implies that iSchools should be understood as a hyped-up brand, that membership merely involves symbols of an elite organisation while actual practices remain 
traditional. The conclusions drawn are that Scandinavian iSchools have remained "in a soil with deeply rooted connections between libraries and a more or less vocational LIS tradition" (72). The iSchool profile is seen as elusive and for the Scandinavian schools it is really LIS "business as usual" (72). Membership, at least for the Scandinavian schools, seems primarily to be an issue of branding. The iSchool movement is characterised as neoliberal.

The value of iSchools beyond the brand constitutes an important discussion involving cultural differences between American and European traditions of library and information science. In the case of the Scandinavian schools, this encompasses both development of LIS as a research area in its own right and a wealth of interdisciplinary collaborations within the human and social sciences as well as technological research. In the case of SSLIS such developments have been ongoing for many years preceding the iSchool application and have continued after membership. Unfortunately, the "Cult of the 'I'" article does not supply any basis for contextual discussions and we need therefore to focus this response on misunderstandings.

\section{The qualitative study}

The "Cult of the "I"" article attempts to understand "considerations made by LIS departments before submitting applications" (53). This leads to selection of one document for each Scandinavian school. Two internal, prior to the application process documents are used in the case of the Swedish and Norwegian schools. For Denmark, a conference presentation is selected (Borlund, 2011). Notably, that publication came two years after certification and the choice of this document is therefore not congruent with stated selection criteria (above).

These documents should not be read as policy statements. Warnings against such interpretation are also specifically given. The Danish text states that "the present paper represent the viewpoint of the author and is as such not an official or formal introduction to the Royal School of Library and Information Science, 
Denmark" (Borlund, 2012, 17). The article is a five page presentation of the Royal School of Library and Information Science. Only two pages deal with iSchools-membership, primarily with activities of branding taking place after caucus membership.

The Swedish text begins with a cautionary note that what follows should not be read as an evaluation of how the iSchools model relates to the current goals and strategies of SSLIS (Doracic, 2012, 3). Furthermore, there is a close association between the Norwegian and Swedish texts, which is acknowledged in the "Cult of the "I'" article ("the Norwegian report builds explicitly on the report from Borås" (55)). This makes it difficult to talk about two separate documents. The report from SSLIS (which the authors consistently refer to as Borås) consist mainly of a literature review and an interview study. These were also found to be valuable and valid for the Norwegian application process. The two texts are therefore informed by the same literature review and interview study.

Numerous segments describing the content of the selected internal report Doracic (2012) at SSLIS are misunderstood as that text does not include any policy statements or expressions that can be read as such. The reoccurring syntax in the "Cult of the "I'" can be described as statements regarding earlier literature and the interview study which involves discussions of branding are interpreted as "SSLIS talks about branding". For instance: "Discussing the presumed advantages in becoming an iSchool, the report emphasises five aspects" (54). It is not the author of the report that makes such claims. The "Cult of the 'I'" article refers to summary of an interview study. Similarly, it is stated that in "a discussion of the presumed disadvantages, the report focuses on primarily three issues" (54). This refers to a segment of the report that reviews earlier literature, listing disadvantages identified in that material. These kinds of misunderstandings dominate the characterisation of the SSLIS position and are, arguably, meaningless as support for the arguments relating to "symbolic moves".

The "Cult of the 'I"' authors appear to look for evidence that iSchool-membership supplies no advantages beyond branding. Therefore, they close their section on the Swedish report by stating (54): "In weighing the pros and cons, the report refers previous research that in many aspects indicates that iSchools 
membership does not make any real difference." Crucially, the report does not involve any weighing of pros and cons. Rather, there is one segment on advantages, building on the interview study and another on disadvantages, utilizing previous literature.

In summary, we find that the qualitative study builds on inappropriate material for the purpose of the article. It is particularly problematic to use texts as policy statements when such a usage is explicitly put forward as inappropriate by the authors themselves. The quantity of the material is also slim. One would expect selection of several documents for each school as well as inclusion of other types of qualitative material in order to be able to make any substantial conclusions. Furthermore, it is important to emphasise that statements summarising an interview study or reviewing earlier literature cannot be understood as policy positions.

\section{The quantitative study}

The purpose of the "Cult of the 'I'" article would appear to encourage a qualitative approach. This would seem to be particularly pertinent as there are such obvious differences regarding the way that courses are designed. Why not undertake a textual analysis of a select number of course plans involving the same kind of course content at the different schools? This could have been followed up by in-depth interviews to explore symbolic and ideological dimensions that firstly led to the decision to apply for membership and then to explore the implications of these dimensions after membership was granted. Instead, the authors proceed with statistical processing that in several ways is questionable.

We are told that the selected courses were processed with a "statistical curriculum comparison" (56) in order to "get a point of departure for analysing them in relation to the ideas of organisational symbolism and to the American implementation of iSchools ideals" (56). The term "statistical curriculum comparison" is a conceptual innovation made in this text. What, then, does the term refer to? It is an attempt at transferring category data (427 courses) into quantifiable data and thereafter to pursue statistical 
correlation. This is an unexpected procedure given the expressed purpose of probing organisational symbolism.

Making numeric data out of category data, in this case titles of courses, is difficult and frequently problematic. The method chosen here is to position courses within the JITA Classification System of LIS. This is a hierarchical system, and such are not suitable for sophisticated mathematical processing. Course titles have no obvious mathematical relationship with each other.

The quantitative data involving available master courses is also problematic, actually incorrect, allowing for misleading conclusions. On pages 56-57 the authors run through their data, Illinois has 198 courses, Indiana has 81 courses, Simmons 88 , Copenhagen has 39 , Oslo 8 and Borås 13 . With this, Oslo and Borås are described as having exceptionally restricted amount of courses compared to the others. In the case of SSLIS (Borås), the correct number is 26 courses (not counting thesis courses). All the quantitative processing that follows in the article become meaningless when only half of the available courses are included in the data. Unfortunately, this means that quantitative data in the case of Borås remains erroneous and severely underplayed. The article concludes that numerous categories are missing in the available master programs although this to a substantial extent reflects the mistakes made in data collection.

There is another explanation for the marked differences between Scandinavian and US schools which must be pointed out: it should not be possible to interpret all courses as constituting the same quantitative unit as courses can vary in length. In particular, Scandinavian courses tend to be longer than the American. This is initially recognised as it is noted that in "the Scandinavian schools, we see a fundamentally different system for structuring programs on master level, resulting in significantly fewer courses" (57). However, the implications of this are not followed through. The authors do make a brief note about this, suggesting that fewer courses in the Scandinavian programs constituted "something which is expected as a result of different educational systems" (73). Even though these acknowledgments are made in the margins, they are insufficient to communicate what is involved. To simply say that the 
educational systems are different on either sides of the Atlantic Ocean can imply many things. For instance, US programs could be understood as having more students, more staff or better funding. The precise information that US courses usually are shorter is withheld. It is a fundamental problem in the subsequent mathematical processing that different courses can vary from one week to half a semester.

There are several problematic consequences of this asymmetrical data collection. US traditions appear to have more comprehensive programs. The classification system utilised in the investigation clearly favours many classifiable units, i.e. shorter courses, over a tradition which allocates resources into longer but fewer courses. US programs, therefore, appear more diverse. In the Scandinavian programs, such diversity may be packed together within individual courses, perhaps involving numerous JITA-classes. For instance, SSLIS master programs include several course segments oriented toward digital humanities, a subject area that we are told we have no competence within. Double classing of courses would have been appropriate for Scandinavian courses but seem not to have occurred.

Another associated problem when attempting quantitative processing is that sample sizes of the measured variables should be made as similar as possible, or they should be normalised so that statistical commensurability could be met. We have already noted above that "one course" is a problematic unit as it can vary from one to 10 weeks in length. Furthermore, sample sizes are exceptionally different, especially between the US schools $(198,91$, and 88 , courses respectively) and the Scandinavian $(39,13$ and 8 respectively). The Illinois sample is about 25 times larger than that of Oslo and given the central limit theorem it is usually not recommended to process a statistical sample as low as 8 .

\section{Contextual issues}

We are confused by the lack of contextual discussion in the "Cult of the 'I"' article. If the focus is on comparing schools in the US and Scandinavia, it would be appropriate to note some historical and political dimensions. For our part, we understand the US and Scandinavian contexts and traditions of LIS as quite 
different. Furthermore, the existence of alternative approaches in Scandinavia is likely valuable and rejuvenating for the iSchools movement. The article does not mention the lively discussion on the character of future of LIS which has been ongoing for most of this millennium and still lively in recent years. The authors of the "Cult of the 'I"" article appear to have misunderstood the mechanisms involving Scandinavian iSchool membership. They seem to expect a sudden transformation. In the case of SSLIS, we have had a long-standing development of research and education along the lines of the broad iField preceding the application. Membership, then, becomes more a matter of consolidating what has already been done, strengthening collaboration with similarly broadly oriented schools and improving on the standing and impact of LIS within the larger academic community.

\section{References}

Borlund, P. (2011). "The case of the Royal School of Library and Information Science: a European iSchool", Journal of Library and Information Science, Vol. 37 No 1, pp. 11-17.

Doracic, A. (2012). iSchools iCaucus: Innebörd, krav och erfarenheter. Högskolan i Borås, Borås, available at: http://hb.diva-

portal.org/smash/record.jsf?pid=diva2\%3A883936\&dswid=gtm_autoEvent 1486479099204

(accessed June 14, 2017).

Golub, K., Hansson J. and Seldén, L. (2017). "Cult of the "I": Organizational symbolism and curricula in three Scandinavian iSchools with comparisons to three American”. Journal of Documentation, Vol.73 No.1, pp. 48-74. 